\title{
Exercise and Antipsychotic Drugs
}

\section{Mary V. Seeman*}

Department of Psychiatry, University of Toronto, Canada

\begin{abstract}
Background: Exercise has been shown to reduce symptoms in patients with schizophrenia.

Aim: To determine whether exercise has a corresponding effect on antipsychotic side effects.

Method: The Google Scholar database was searched for references to exercise, pharmacokinetics, and antipsychotic drug side effects.

Results: There are no human studies on the effect of exercise on side effects of antipsychotic medications. Clinical experience suggests that exercise increases parkinsonian side effects of intramuscular depot antipsychotics while animal experiments show that the side effects of oral antipsychotics are buffered by exercise.

Conclusion: A difference in bioavailability may explain why exercise increases side effects when antipsychotic drugs are administered in intramuscular depot form, but decrease these effects when antipsychotics are given orally. Human trials are needed.
\end{abstract}

Keywords: Schizophrenia; Parkinsonian side effects; Antipsychotics; Pharmacokinetics; Exercise

Both the beneficial and adverse effects of antipsychotic drugs are known to fluctuate over time even after steady state blood levels of the drug are achieved. This suggests that such effects are influenced, at least temporarily, by a number of endogenous (e.g. mood, stress level, circadian cycle) and exogenous (e.g. diet, interpersonal encounter, environmental change) factors, which may, when taken together, help to explain the significant placebo rate in antipsychotic drug trials [1]. Exercise is one factor that has been shown to temporarily enhance treatment effects in schizophrenia [2-8]. Whether side effects are enhanced or dampened after exercise, however, has not been addressed in these studies. The following case example suggests that physical activity can sometimes increase the side effects of drugs.

\section{Case Example}

Ted was a young patient diagnosed with schizophrenia and treated for many years with antipsychotic fluphenazine enanthate depot injections administered every three weeks. Periodically and always unexpectedly, he would knock loudly on my office door, demanding to be seen at once. The complaint was always the same - that his muscles were stiff, a parkinsonian side effect of fluphenazine. The timing of these knocks was mysterious. They did not correspond to the time since last injection. They did not appear to correspond to any particular life event or emotional upset. Months would pass without any knocks and then there could be three in the same week.

Ted was the one who finally figured it out. The knocks occurred during the months that he played soccer. His injection was in the upper outer quadrant of the buttock, the dorsogluteal muscle, and whenever those muscles were strongly activated as in soccer, blood flow to and from the depot site increased so much that his blood stream was inundated, his brain received more drug, more dopamine receptors were blocked [the mechanism of action of antipsychotic drugs, and, subsequently, his muscles became stiff, an effect of dopamine blockade $[9,10]$. Clinical experience reinforces the observation that side effects to depot intramuscular antipsychotic injection increase after exercise. This motivated a literature review of exercise effects on side effects of antipsychotic drugs, however administered.

\section{Method}

For this mini review, the Google Scholar database was searched with the terms: Pharmacokinetics, exercise, antipsychotics or neuroleptics in combination. Information from the few pertinent references is detailed below.

\section{Depots and Blood Flow}

Exercise diverts blood from other organs to muscle (Figure 1). As a consequence, any drug that is stored in muscle, as is the case for depot medication, is consequently washed more quickly into the bloodstream, increasing its bioavailability and, therefore, its side effects $[11,12]$. First-

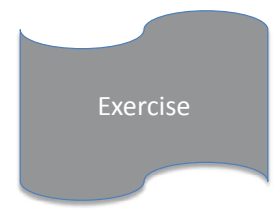

$\begin{array}{ll}\text { Blood away from } & \text { Blood towards } \\ \text { Kidney } & \text { Heart } \\ \text { Digestive system } & \text { Muscles } \\ & \text { Brain } \\ & \text { Lungs }\end{array}$

Less drug absorption through gut, faster drug metabolism

Less elimination by kidneys; more elimination by gut, lungs, and skin

Blood flow to muscles releases drug from muscle stores

Figure 1: Exercise diverts blood from other organs to muscle.

*Corresponding author: Mary V Seeman, Department of Psychiatry, University of Toronto, Canada, Tel: 1-416-486-3456; E-mail: mary.seeman@utoronto.ca

Received: July 17, 2016; Accepted: July 23, 2016; Published: July 30, 2016

Citation: Seeman MV (2016) Exercise and Antipsychotic Drugs. J Pat Care 2: 114 doi: 10.4172/2573-4598.1000114

Copyright: (c) 2016 Seeman MV. This is an open-access article distributed under the terms of the Creative Commons Attribution License, which permits unrestricted use, distribution, and reproduction in any medium, provided the original author and source are credited. 
generation antipsychotic long-acting injections such as fluphenazine enanthate are known to cause a high rate of extrapyramidal sideeffects such as muscle stiffness [13]. The degree of the increase will depend on the intensity, mode, and duration of the exercise. When the effect is small, it may go unnoticed, which is perhaps why it has not been previously reported in relation to antipsychotic treatment. The analogous effect has been well documented, however, in the context of insulin administration in patients with diabetes mellitus $[14,15]$. Exercise involving an extremity that is the site of insulin injection increases the absorption from the injection site and consequently increases systemic bioavailability of insulin. As a result, blood glucose levels can fall sharply, which may sometimes lead to a hypoglycemic crisis.

Besides increasing blood flow, exercise also produces heat, which speeds the diffusion of drug molecules from muscle into blood vessels. Either exercise or the application of local heat or massage at the site of an injection will raise plasma levels of depot drugs [16]. All three probably contribute to the observation that plasma levels vary as much as 40-fold in patients receiving an identical dose of depot antipsychotic $[17,18]$. Since exercise programs have become part of the comprehensive treatment of schizophrenia, the question of exerciseinduced antipsychotic side effects becomes increasingly important [19].

\section{Oral Antipsychotics}

When drug is stored in muscle depots, the effect of its release into the bloodstream by exercise swamps the multiple effects of exercise on drug elimination. For oral drugs, the effects of exercise are more complicated, affecting absorption and clearance in different ways [12,20,21]. Drug absorption is affected in two major ways. The heat generated during exercise increases molecular movement and, consequently, speeds the diffusion of drug molecules from the gastrointestinal tract into the blood stream. But this effect is offset by the diversion of blood from gut to muscle. The elimination of drugs is increased from sweating and faster breathing, but urination is decreased (Figure 1). The net effect probably varies with the duration and intensity of the exercise as well as with a host of individual factors [22-24].

\section{Animal Experiments}

Both individual factors and exercise variables can be kept constant in laboratory animals as they cannot in human beings. Administration of drugs to rodents, whether in the drinking water or by intraperitoneal injection, is more akin from a pharmacokinetics viewpoint to human oral administration than to depot intramuscular administration (since there is no release of stored drug). An experiment in rats that looked at the effects of physical exercise on akinesia, dystonia, gait alteration (analogues of parkinsonian symptoms in humans) induced by chronic administration of the antipsychotic drug, haloperidol, found side effects to be reduced. Forty-eight rats were placed into four groups: control, exercise, haloperidol, and haloperidol + exercise. All the animals received a daily intraperitoneal injection of saline or haloperidol for 30 days, and the exercise groups underwent a daily $30 \mathrm{~min}$ exercise protocol (treadmill, swimming) for 20 days. To test for side effects, the animals were subjected to the ink-paw test, bar test and open-field test throughout the training period. The results were that exercise alleviated the following haloperidol-induced side effects: akinesia, shortened stride length, and increased stance width [25]. Extrapolating from the animal work, exercise is predicted to diminish side effects of oral antipsychotic drugs. The possibility of increased side effects from depot injection, however, continues.

\section{Conclusion}

The bioavailability of antipsychotic medication, while it may be increased after exercise for individuals receiving intramuscular depot antipsychotics, is not likely to be increased for those on oral medication. Since most individuals with schizophrenia are treated with oral rather than depot drugs, this is reassuring. Since more side effects also mean higher therapeutic drug levels in the blood, it could mean that patients on depot antipsychotic drugs improve substantially more with exercise than those on an oral regimen. This should be tested.

\section{References}

1. Rief W, Barsky AJ, Bingel U, Doering K, Schwarting R, et al. (2016) Rethinking psychopharmacotherapy: The role of treatment context and brain plasticity in antidepressant and antipsychotic interventions. Neurosci Biobehav Rev 60: 51-64

2. Dauwan M, Begemann MJ, Heringa SM, Sommer IE (2016) Exercise improves clinical symptoms, quality of life, global functioning, and depression in schizophrenia: A systematic review and meta-analysis. Schizophr Bull 42: 588599.

3. Firth J, Cotter J, Elliott R, French P. Yung AR. (2015) A systematic review and meta-analysis of exercise interventions in schizophrenia patients. Psychol Med 45: 1343-1361.

4. Gorczynski P, Faulkner G (2010) Exercise therapy for schizophrenia. The Cochrane Library 12: CD004412.

5. Scheewe TW, Backx FJ, Takken T, Jörg F, Strater AV, et al. (2013) Exercise therapy improves mental and physical health in schizophrenia: A randomised controlled trial. Acta Psychiatr Scand 127: 464-473.

6. Vancampfort D, Probst M, Helvik Skjaerven L, Catalán-Matamoros D, LundvikGyllensten A, et al. (2012) Systematic review of the benefits of physical therapy within a multidisciplinary care approach for people with schizophrenia. Phys Ther 92: 11-23.

7. Vera-Garcia E, Mayoral-Cleries F, Vancampfort D, Stubbs B, Cuesta-Vargas A (2015) A systematic review of the benefits of physical therapy within a multidisciplinary care approach for people with schizophrenia: An update. Psychiatry Res 229: 828-839.

8. Wu MH, Lee CP, Hsu SC, Chang CM, Chen CY (2015) Effectiveness of highintensity interval training on the mental and physical health of people with chronic schizophrenia. Neuropsychiatr Dis Treat 11: 1255-1263.

9. Van Rossum JM (1967) The significance of dopamine-receptor blockade for the action of neuroleptic drugs. Neuropsychopharmacol 5: 321-323.

10. Marsden CD, Jenner P (1980) The pathophysiology of extrapyramidal sideeffects of neuroleptic drugs. Psychol Med 10: 55-72.

11. Ciccone CD (1995) Basic pharmacokinetics and the potential effect of physica therapy interventions on pharmacokinetic variables. Phys Ther 75: 343-351.

12. Van Baak MA (1990) Influence of exercise on the pharmacokinetics of drugs. Clin Pharmacokinet 19: 32-43.

13. Barnes TR, Curson DA (1994) Long-term depot antipsychotics. A risk-benefit assessment. Drug Saf 10: 464-479.

14. Koivisto VA, Felig P (1978) Effects of leg exercise on insulin absorption in diabetic patients. New Eng J Med 298: 79-83.

15. Koivisto VA, Felig P (1980) Alterations in insulin absorption and in blood glucose control associated with varying insulin injection sites in diabetic patients. Ann Int Med 92: 59-61.

16. Tuninger E, Levander $S$ (1996) Large variations of plasma levels during maintenance treatment with depot neuroleptics. Br J Psychiatry 169: 618-621.

17. Funk KA, Bostwick J (2013) Paliperidone palmitate injection site. Issues Ment Health Nurs 34: 779-782.

18. Wiles DH, Gelder MG (1979) Plasma fluphenazine levels by radioimmunoassay in schizophrenic patients treated with depot injections of fluphenazine decanoate. Br J Clin Pharmacol 8: 565-570.

19. Bredin SS, Warburton DE, Lang DJ (2013) The health benefits and challenges 
of exercise training in persons living with schizophrenia: A pilot study. Brain Sci 3: 821-848.

20. Døssing M (1984) Effect of acute and chronic exercise on hepatic drug metabolism. Clin Pharmacokin 10: 426-431.

21. Khazaeinia T, Ramsey AA, Tam YK (2000) The effects of exercise on the pharmacokinetics of drugs. J Pharm Pharm Sci 3: 292-302.

22. Lenz TL (2010) Pharmacokinetic drug interactions with physical activity. Am J Lifestyle Med 226-229.
23. Lenz TL, Lenz NJ, Faulkner MA (2004) Potential interactions between exercise and drug therapy. Sports Med 34: 293-306.

24. Persky AM, Eddington ND, Derendorf H (2003) A review of the effects of chronic exercise and physical fitness level on resting pharmacokinetics. Int $\mathrm{J}$ Clin Pharmacol Therap 41: 504-516.

25. Baptista PP, de Senna PN, Paim MF, Saur L, Blank M, et al. (2013) Physical exercise down-regulated locomotor side effects induced by haloperidol treatment in Wistar rats. Pharmacol Biochem Behav 104: 113-118. 